short, special section on histochemical methods has been added, though the value of such a separation may be questioned, since many of the standard staining methods are, in effect, histochemical. If this section is continued in future editions it would be well to furnish it with cross-references to appropriate staining reactions included in other sections.

An introduction on the principles of fixation emphasizes some important points which are often forgotten, while the section on fixatives is limited to a selection of those in general use, a wise restriction in view of the innumerable 'modifications', of doubtful value, which have found their way into print. In the section on embedding and mounting media one is glad to see the glycols coming to the fore, though the treatment given does not exhaust their possibilities in this connexion.

The section on staining methods for animal histology lists 170 techniques with operational schedules. The botanical section contains sixtyeight methods, though the two sections are by no means mutually exclusive. For example, the animal section gives thirty-nine methods employing hæmatoxylin and the botanical section only four, but many of the former also have botanical uses. Source references are given for most of the newer methods in each section.

There is a new section on fluorescence microscopy which is a useful introduction to this important technique and another section of seventy-six iterns on smear preparations. It is in this last section that most of the microbiological methods cited are to be found, though there is room for a good deal of expansion in this connexion. It would surely be better to separate the microbiological methods under that name, apart from blood film stains and other types of smear. Incidentally there is no mention of the extremely important cellular smear techniques for the study of meiosis, which have become indispensable in genetic studies. A number of appendixes give formulæ, refractive indices, and other useful data, in particular the solubilities of reagents and stains, which are often troublesome to discover.

Altogether this edition has markedly improved the value of the book as a laboratory companion and it should be in the hands of every microscopist.

R. C. MCLEaN

\section{THE GRANITE CONTROVERSY}

\section{The Granite Controversy}

Geological Addresses Illustrating the Evolution of a Disputant. By Prof. H. H. Read. Pp. xix +430 . (London : Thomas Murby and Co., 1957. Distributed by George Allen and Unwin, Ltd.) 42s. net.

$\mathrm{N}$ the controversy on the origin of granitic rocks 1 which has stirred geological thinking in the past two decades Prof. Read has played a prominent part, and here in compact form are presented eight of his published contributions delivered as presidential or other addresses between the years 1939 and 1954 . They provide a stimulating and entertaining record, confessedly for the most part of one side of the controversy, and reflect clearly the progressive evolution of his own ideas. The author as a protagonist of wet granitization has not spared rival hypotheses, but all has been done with good humour, and what is more, the story is enlivened by frank confessions of his own misinterpretations, so that none has cause to take offence.

The new matter now provided appears in a short preface to the volume, reviewing the major points of contention, the course of the author's own deductions and a summary statement of his present position.

The disclosures are revealing. The changing outlook is reflected in the ultimate scepticism on 'basic fronts' once so favourably regarded, a revision of views of dents de cheval and what appears to be a recantation on rapakivi.

These are moves which will be welcomed by the rival champions of magma and deplored by the solid diffusionists.

The development of the idea of a granite series in time and place, surely to be recognized as a fruitful conception, followed without doubt a clearer appreciation of the point of view of the magmatist.

Let it be said at once that the magmatist has also moved. Most have conceded a place for granitization though the medium assigned an active role has been primarily granitic liquid or its emanations, and there has been, since Bowen and Tuttle's studies, increasing recognition of the crystalloblastic texture of many granites traced to a magmatic origin. The nature of the 'emanations' postulated by the wet granitizer is seldom disclosed, though the conception that "each country rock took what it wanted to make itself into granite" doubtless gives him the required answer.

Prof. Read's later preference traces the origin of the emanations responsible for granitization to the lower and basic part of the crust (the sima), and though he held and holds that "granites and basalts are different things .... in their ultimate source they may thus be closely and genetically connected".

This is indeed a concession, and a further sign that the author is moving to a middle position in the continuing disputation.

The line of evidence provided by the experimental laboratory approach to the subject of granite finds little favour in the author's discourses.

"Many of us, fortunately, prefer the field to the crucible and the triangles and more complex geometry that seems to go with them," indeed sums up his outlook on this question. Yet much of the present controversy is the product of conflicting interpretations of field evidence, a position reflecting in many cases the inadequacy of the field relations for reaching a firm decision.

All data relevant to the problem need to be pressed into service, and the neglect in this discussion of the results of experimental study on the mineral phases of granite is to be regretted, the more so now that the techniques of investigating wet mineral silicates at high temperatures and pressures have been successfully developed, and much new data critical for the interpretation of the granite system already made available.

Even the "consolidated bibliography and full index" which the author provides to enable the reader "to seek the truth for himself" omits reference to the literature on these experimental investigations.

Though this approach to the problem still remains a field for Prof. Read's meditations, it is pleasant to reflect that his evolution has brought him already to a middle position in the controversy, indeed to that receptive state which augurs well for further real advances. $\quad$ C. E. TrLLEY 